Reinforcing Marginality?

\title{
Maternal Health Interventions in Rural Nicaragua
}

\author{
Birgit Kvernflaten
}

Centre for Development and the Environment, University of Oslo, Norway

P.O. Box 1116 Blindern 0317 Oslo, Norway

Phone: 004722858794

Email: birgit.kvernflaten@sum.uio.no

Birgit Kvernflaten is a PhD Candidate at Centre for Development and the Environment (SUM), at the University of Oslo, Norway. Her research has focused on reproductive health and maternal health in Guatemala and Nicaragua, exploring local perspectives in the context of policies and interventions.

Her current $\mathrm{PhD}$ research concerns maternal health among rural women in Nicaragua, in particular the policies and practices of the health system in relation to maternal healthcare, and how maternal health interventions encounter local socio-cultural realities. 


\title{
Reinforcing Marginality? \\ Maternal Health Interventions in Rural Nicaragua
}

\author{
Birgit Kvernflaten* \\ Centre for Development and the Environment, University of Oslo, Norway
}

\begin{abstract}
To achieve Millennium Development Goal 5 on maternal health, many countries have focused on marginalized women who lack access to care. Promoting facilitybased deliveries to ensure skilled birth attendance and emergency obstetric care has become a main measure for preventing maternal deaths, so women who opt for home births are often considered 'marginal' and in need of targeted intervention. Drawing upon ethnographic data from Nicaragua, this paper critically examines the concept of marginality in the context of official efforts to increase institutional delivery amongst the rural poor, and discusses lack of access to health services among women living in peripheral areas as a process of marginalization. The promotion of facility birth as the new norm, in turn, generates a process of 'remarginalization', whereby public health officials morally disapprove of women who give birth at home, viewing them as non-compliers and a problem to the system. In rural Nicaragua, there is a discrepancy between the public health norm and women's own preferences and desires for home birth. These women live at the margins also in spatial and societal terms, and must relate to a health system they find incapable of providing good, appropriate care. Strong public pressure for institutional delivery makes them feel distressed and pressured. Paradoxically then, the aim of including marginal groups in maternal health programmes engenders resistance to facility birth.
\end{abstract}

\section{Keywords}

Nicaragua; ethnography; maternal health; marginality: public health

\footnotetext{
*Email: birgit.kvernflaten@sum.uio.no
} 


\section{Introduction}

In the past decade, many countries have accelerated their efforts to reduce maternal mortality and reach Millennium Development Goal (MDG) 5 on maternal health. This involves a focus on women that in the public health discourse are referred to as 'hard to reach', 'vulnerable' or 'marginal'. They lack access to the health services deemed necessary for averting maternal deaths: skilled birth attendance and emergency obstetric care. Targeted interventions aim to improve maternal health outcomes among such 'marginal women', ${ }^{1}$ for instance by improving access to skilled birth attendance, but rarely consider women's own perceptions of their needs and preferences, or their own experiences of being designated as marginal (Ecks and Sax 2005).

Nicaragua has achieved reductions in maternal mortality, but still struggles with inequality in access and quality of care. Reaching the most marginalized women remains a challenge. To this end, the government has made efforts to reduce maternal deaths among poor rural women, focusing on facility-based deliveries (Kvernflaten 2013). Drawing on ethnographic research in rural Nicaragua, this paper explores the concept of marginality in maternal health. Through analysis of such spatial and societal dimensions of marginality as poverty, gender, social class and physical access to services, this paper critically examines how Nicaragua's health system and specific maternal health strategies - notably the new focus on institutionalized delivery - create and reinforce marginality. This new focus and 'norm' generate a process of 're-marginalization': While rural poor women were already defined marginal because of poor maternal health, the re-definition of the norm make public health officials disapprove of women who give birth at home, and brand them as noncompliers and as a problem to the health system. Behind this incongruity between the public health norm and women's own preferences and desires for home birth are not only cultural factors, but also women's assessments of health facilities as incapable of providing good, appropriate care. Some women experience the ongoing process aimed at including marginal groups in maternal health programmes as pressure to comply with government policy, which results in resistance to facility birth that furthers distancing women from services.

\section{Marginality, health and the 'normal'}

Discussions of marginalization usually include the idea of excluded groups, often described in terms of spatial and societal marginality. Spatial marginality is primarily about physical location and distance from the centre, and how individuals or groups are poorly integrated into a system (Gurung and Kollmair 2005, 10-11; Leimgruber 2004). Societal marginality 
relates to social conditions - the economic, social and political disparities between marginal and mainstream populations, as manifested by poor livelihood, low participation in public decision-making, and discrimination and stigmatization due to race, ethnicity, gender, age, religion etc. (Gurung and Kollmair 2005, 12). Perspectives and interpretations of marginalization vary, but a common understanding is that this involves a process of being made marginal, whereby the political system and societal and institutional structures, or individuals, operate to deny other individuals, social groups and communities full privileges, rights, access and power (Ray 1996, xv; Ford and Yep 2003, 243). Marginalization is a complex process whereby certain people and ideas become privileged, while others are ignored, trivialized, rendered invisible and unheard, deemed inconsequential, de-authorized as 'other' or threatening (Tucker 1990, 7). People become marginalized when their perspectives are disregarded or excluded (Tsing 1993, 5), implying that 'marginal people' are considered less important to the mainstream (Ecks and Sax 2005, 200). However, when marginality is linked to processes of uneven development (Peattie 1980), the marginal and excluded paradoxically become of central importance as targets of development. Health planners, workers and advocates often define 'marginal people' as needing more healthcare, more doctors and more medicine (Ecks and Sax 2005). The question, therefore, is what happens when the theoretically invisible become highly visible in particular ways?

'Marginal women' have become targets for maternal health programmes aimed at reducing maternal mortality and morbidity. Biomedicine has acquired the status of authoritative knowledge in defining maternal health 'needs' (Davis-Floyd and Sargent 1997; Jordan 1993). Public health rationales have underpinned the organization of maternal health services in the pursuit of population-level maternal mortality reduction, rather than individual women's preferences or needs. Biomedicine and public health have assumed the power to define the 'standards of normality' to which people are expected to conform (Das and Poole 2004, 10; Ford and Yep 2003, 244). From a public health perspective, there is consensus that the best way to reduce population-level maternal mortality is to ensure access to skilled or professionalized birth attendants and referral facilities for obstetric emergencies (Yamin and Boulanger 2014). Although skilled birth attendants may attend home births, efficiency considerations have made institutionalized delivery the norm in programmes aimed at reducing maternal mortality. From this perspective, women who - for whatever reason - do not avail themselves of institutionalized delivery can be considered 'marginal' and in need of targeted intervention. 
What is often ignored, is that these 'marginal women' have their own desires, aspirations and agency, and experiences of what it means to live at the 'margins' (Ecks and Sax 2005, 201). It is pertinent to explore marginality not solely by public health standards, but also in terms of local understandings of health and well-being (Polit 2005, 226). It is easy to assume that poor people have health 'needs' like for instance obstetric care when they do lack access to health services, rather than desires for a certain birth experience (cf Fischer and Benson 2006, 2-3). Health needs are 'real' - many people lack access to healthcare and obstetric care. Importantly people also have 'desires'. Mapping desire involves understanding what matters to people, what seems important, meaningful and vital, also recognizing that desires are shaped by collective experiences, local social processes and political economic structures (Fischer and Benson 2006, 12-13, 160). This is not to make a simple distinction between health needs and desires, but to remind us that desires and aspirations may differ from, or even be in conflict with, what public health - 'the centre'- defines as 'normal' and as 'needs'. If the primary objective of public health is to ensure the health of the population, this may come at the expense of the desires or even the biomedical 'needs' of individuals.

For Das and Poole (2004), understanding the 'margins' is linked to an understanding of the state and its disciplinary procedures. 'Margins' are peripheries inhabited by people considered insufficiently socialized, whom the state attempts to 'manage' and transform into lawful subjects of the state (Das and Poole 2004, 9). Das and Poole emphasize the importance of recognizing that power exercised by the state is also about bodies $(2004,10)$ : for instance, how maternal health has become a central focus of development and state interventions. Margins are not solely geographically defined, nor is the state absent: margins are related to everyday practices of the state $(2004,19)$. Health interventions, for example, impacts on daily life at the margins. By the definition of what is normal, or preferred practises, such state practises construct and re-construct the margins.

Marginality is thus a fundamentally relational concept: the centre and its margins constitute each other, with the boundaries between them constantly shifting (Ecks and Sax 2005, 199; Reddy 2005). 'Normality' in public health is as such constantly defined and redefined. Whereas the use of traditional birth attendants to reduce maternal mortality was the 'norm' a few decades ago, in the era of the MDGs this 'norm' involves skilled birth attendants and institutional deliveries, shifting traditional birth attendants and home births from the centre to the margins. It is this perspective of margins not as fixed but as continuously being defined and re-defined in relation to the perceived 'centre' and the concepts of 'normality' as defined at the centre that informs this paper's analysis. 


\section{Methods}

This paper draws on ethnographic research during five months in 2012 in a rural municipality in the mountainous areas of Matagalpa, Nicaragua, focusing on the intersection between maternal health interventions and local socio-cultural realities. The strength of ethnographic fieldwork is the possibility of engaging directly with research subjects in their local contexts, which enables and encourages the researcher to revise concepts according to local views and experiences (Ecks and Sax 2005, 202). Studying local experiences can shed light on how the 'margins' experience medical interventions (Feierman et al. 2010, 123), and is essential for adjusting services to what the people themselves perceive as their needs. This study has employed participant observation and interviews as key methodological tools. The author attended brigadista (community health workers) training sessions, outreach clinics, and hospital meetings to explore health workers' perceptions of women's marginality and their strategies for including women in maternal health programmes, as well as accompanying seven brigadistas and parteras (traditional birth attendants), in their daily work including home visits to pregnant women. A total of 29 fieldtrips to 22 different communities and barrios (neighbourhoods - around the municipality's main town), were undertaken. In focus were women who do not access healthcare services - the most 'marginalized' - in order to explore the factors that influence access to, use of and perceptions of maternal health services. In addition, the author conducted open-ended interviews (in Spanish) with 72 women and men from 28 different communities and barrios, and 15 brigadistas and parteras, five local hospital workers, four women working at the casa materna (maternity waiting home), four municipal politicians and 11 NGO representatives working in the area. The NGOs were international, national and local, working on health issues and/or women's health and rights. The author took comprehensive notes throughout the interviews, and further elaborated on them after the interviews. The analysis was thematic, involving identifying patterns, regularities, or themes emerging from the data.

\section{Nicaragua: Health system, maternal health strategies and the 'marginalized'}

In state policies on development and health in Nicaragua, the term 'marginalized''marginados', is used interchangeably with terms such as 'poor', 'rural', 'peasant', 'uneducated', and 'with poor access to healthcare'. Historically, Nicaragua has been a country with extremely unequal distribution of wealth. During the 43-year long Somoza dictatorship that was overthrown in 1979 , medical care was inaccessible to the majority of the population, 
especially the poor living in rural areas (Tesler 2010). The 1979 socialist revolution led by FSLN (Sandinista National Liberation Front) aimed to improve medical care to the poor and marginalized. Equally, returning to power in 2007, FSLN has proclaimed to work for the poor and marginalized and provide improved medical care. When the current FSLN government uses the term marginados it refers to the population marginalized during the Somoza dictatorship, or, people marginalized under the previous 16 years of neoliberal government before returning to power. Used politically, FSLN recognizes the term as a relational concept and as a social process: people are marginalized by others (Ecks and Sax 2005, 208). The government speaks of marginality in the sense of saving the excluded, and politically it becomes important to reach all marginal people.

The government and NGOs working on women's health generally understand women living in rural poor areas as 'marginal', an understanding underpinned by statistics showing high rates of maternal mortality among the poor, rural populations in the north-central and eastern provinces. In a 2007 report, MMR (maternal mortality ratio per 100,000 live births) estimates in these areas ranged from 180.6 to 214.9 (Pan American Health Organization 2007). The municipality in Matagalpa, the north-central mountains of Nicaragua where this study was conducted, had three registered maternal deaths in 2011, and a MMR of 150, roughly estimated. ${ }^{2}$ However, these figures are disputed. The government claims the MMR has been reduced dramatically, giving an estimate of 78.4 for Matagalpa in 2011, even as low as 25.3 (national average 49.7) in 2012 (Ministerio de Salud 2014). The government has been criticized for withholding information on how the statistics are collected, for concealing information, for excluding indirect maternal deaths, and for pressuring local health authorities to the extent that they report lower figures, all to show progress towards MDG 5 (López 2014). The government even banned from 2010 and onwards a local NGO working on women's rights from conducting analyses of maternal mortality in the area (Kvernflaten 2013). Critics also cite the country's high ratios of adolescent pregnancies and domestic violence (personal communication 2012); further, that the 2006 law making all abortions illegal, even to save the woman's life, obscures the actual figures by deterring women from seeking healthcare (Silva 2010).

Another way health authorities and NGOs understand and describe marginality is by dividing women into those who give birth in a health facility and those who do not, which was the main concern for the health authorities at the local level. There are also disagreements as regards the percentage of home births. According to a government report, home births accounted for 16\% in Matagalpa in 2012 (25\% on the national level) (Ministerio de Salud 
2014), whereas local health professionals and local NGOs estimated the figure at around 30$50 \%$ the same year (personal communication 2012). In any case, as a central official strategy for reducing maternal mortality, manifested in policies and programmes, the ultimate aim is facility-based delivery for all women, reflecting the emphasis on skilled birth attendance as a main performance indicator. Skilled birth attendance is the proposed MDG target because it was considered essential for identifying and referring obstetric complications, and importantly also because skilled birth attendance was deemed easier to measure than maternal mortality (Austveg 2011). In fact, skilled birth attendance is not easy to measure or operationalize, and the skills of the 'skilled providers' have been questioned (Harvey et al. 2007; Yamin and Boulanger 2014; Spangler 2012).

Unquestionably, Nicaragua has shown improvements in maternal mortality in recent decades. Further reduction is a central strategic aim of the government in relation to health, reflected in its commitment to the MDGs (Pan American Health Organization 2008) and by the involvement by global agencies and donors in strategies, planning, funding and implementation of health policy (Pan American Health Organization 2007; Kvernflaten 2013). Nicaragua has been granted performance-driven loans (in 2005) to reduce maternal and infant mortality, and loan (in 2011) to focus in particular on vulnerable provinces, among them Matagalpa (USAID 2008; Inter-American Development Bank 2004, 2011). With skilled birth attendants becoming what is deemed 'normal', getting 'marginalized women' to give birth in health institutions has assumed great importance. The focus on skilled birth attendance has resulted in massive pressure on performance at the local level (Kvernflaten 2013).

\section{Spatial and societal marginality in Nicaragua}

When health professionals and local NGOs described the women who do not have hospital deliveries, they often mentioned issues of distance, transportation, money, culture and machismo $^{3}$, thus defining marginality in spatial and societal terms. These issues however, are not necessarily limited to rural remote areas. Health services have improved following Nicaragua's socialist revolution in 1979, yet access to adequate care remains unequal. Most health facilities are located in urban areas. In the departments/regions there is typically a regional hospital, a health centre or a primary hospital in the main town in the municipality, and a few health posts located in smaller communities.

The municipality studied has a primary hospital in the main town, and eight health posts in rural communities. These health institutions serve approximately 67000 people living 
in some 186 communities. Many communities lie hours away from a health institution, with poor roads and no mechanized transport options. A community may be closer to a health post that provides antenatal care, but the primary hospital is the only officially recognized place for delivery in the municipality. Health posts usually do not have beds or the basic equipment to handle deliveries, nor are they open in the evening or at weekends. Although the government aims to get more specialists to rural areas, at the time of fieldwork, the presence of an obstetrician at the primary hospital was irregular and confined to weekdays. There were other doctors, several nurses, and one or two nurses with obstetric skills. ${ }^{4}$ According to a Unicef report, the percentage of skilled attendants at birth in rural areas were $56 \%$ against $92,4 \%$ in urban areas (Unicef 2012), although the skills of these 'skilled attendants' remain unclear.

To be marginalized in spatial terms means long distances, with poor or no roads or transport. When labour starts, some women express that they choose to stay at home, rather than making the long, difficult journey to the hospital. A 31-year-old woman from a community some two hours' walking distance from the nearest health post, pregnant with her ninth baby, explained:

There is no public transport. The road is in very bad condition. There are no cars here, and when labour starts we have to walk a long way just to get to the road. It's safer to stay at home.

A widow with 11 children, living in a poor, remote community three hours by foot and bus from the nearest health post, gave a similar account of distance and transport, and added: 'The problem is if there is an emergency. Then we have to carry her to the road and try to find transport.'

Efforts to deal with spatial marginality include the casa materna, the maternity waiting home, close to the primary hospital. Women should come eight to fifteen days before due date. This casa materna ${ }^{5}$ could accommodate approximately 20 women and was usually full. For women who want to give birth at the hospital but live far away the casa is important. It is supposed to be free of charge, but several women staying there had paid 25 córdobas (roughly USD 1). Those unable to pay the fee should bring food. The casa's workers underlined that the casa had lost its funding. Women also worried about paying for prescribed medicines and the cost of transport. With many unable to pay, poverty becomes part of the marginalization process, even when healthcare is free. Women also spoke of having to leave their children and animals at home with nobody to take care of them. They frequently 
described how husbands refused to let their wife go to the casa materna, the hospital, or even leave the house. 'They are machistas and celosos [jealous], and will not let another man [the doctor] see their woman', a young woman explained. A 30-year-old woman living only a 40minute walk from the hospital, but who had given birth to all her five children at home, explained: 'I can't leave the house and the children, and my husband wants to deliver the babies himself'. A nurse at the hospital described how husbands even guard their wives with machetes. Although this might be a metaphor describing the situation, the nurse mentioned a case where a woman haemorrhaged to death during home birth, because her husband would not let her go to the hospital or let anyone enter the house.

Women have difficulty in accessing services due to the spatial and societal marginality described above. Yet behind the definition of such women as 'hard to reach', these diverse reasons of distance, transportation, money, or husbands' choices affect women differently. While such spatial and societal dimensions of marginality as poverty, gender, social class and physical access to services constrain women from accessing services, several women reported that they want, or have had, a hospital delivery because they consider it safer. 'At the health posts they told me something could go wrong and I might die', an older woman explained. Hospital delivery was often assessed as 'safer' in view of possible obstetric complications.

\section{The community-based health system - a societal aspect of marginality}

In seeking to reach all women, Nicaragua's health system is very dependent on the work of brigadistas - community health workers - in remote areas. The community, often with assistance from hospital health educators, selects the brigadista, who also often inherit the role from family members. The official goal is at least one brigadista in each community. They work without pay, but receive training sessions at health facilities once a month. A main theme at these sessions is maternal health, and one of the brigadistas' chief tasks is to identify and report statistics on pregnant women in their communities. As part of the strategy to promote facility-based birth, they are expected to visit all pregnant women, refer them to antenatal care, and promote the casa materna and hospital deliveries (Kvernflaten 2013). Brigadistas thus do provide health information, follow up on women and provide support in accessing health services, and having access to brigadistas may make local women less vulnerable. More than half of the communities in the municipality have at least one brigadistas, although their activity level varies. Women in communities without a brigadista may also access healthcare, but for women living in difficult social conditions, the presence of a brigadista can ease their situation. For instance, the brigadista attend to women in situations 
of domestic violence, or when husbands refuse to let their wives see a doctor. One older partera and brigadista from a community not far from the primary hospital, explained: 'When the man does not want his wife to go to the hospital, I keep going to her house. That's why I am here.' The brigadista provides information and can serve as an important link to the hospital in emergencies. Women in communities without a brigadista often stressed they missed having someone to talk to or to accompany them to the hospital.

Brigadistas are a major strength of the health system. Paradoxically, the communitybased health system nevertheless contributes to the process of marginalization. The Nicaraguan health system lacks the capacity to reach all remote, rural communities. Moreover, the use of community health workers is often encouraged where the health system is weak. Community health workers are an inexpensive way of organizing healthcare in such remote rural areas. The health system has difficulties reaching the areas without brigadistas, thus creating a structurally-related form of marginality that also illustrates how issues of spatial and societal marginality operate interdependently in complex and intersecting ways (Ford and Yep 2003, 243). These spatial and societal aspects of women's marginality in maternal health act to exclude women from accessing healthcare - healthcare that women both need and desire. That said, some women do not want to give birth at a health facility: they have different desires.

\section{'Marginal desires'}

Gloria is a woman with such different desires. Having desires that differ from the norm defines Gloria as marginal and therefore in need of targeted interventions to include her in hospital maternal care. At 18, Gloria had just given birth to her second child. Gloria and her family live in a poor barrio, located close to the primary hospital. Despite the short walking distance, she gave birth at home, even though the hospital personnel had urged her to go to the hospital. Gloria was hiding when the author visited her house, and both Gloria and her husband seemed upset by the visit. She was frightened that someone from the hospital would come and scold her for giving birth at home. Gloria had to be convinced that this was not a visit from the Ministry of Health before she would even admit to having given birth to her son at home. 'I went to a few antenatal check-ups, but I will not deliver my baby at the hospital', she finally declared. Gloria explained how she saw hospital delivery practices as an insult: grosería. Gloria referred especially to medical procedures as cutting and stitching and how hospital personnel cleaned and cared for the women after birth. While an episiotomy (cutting) is recommended in biomedical protocols when indicated, women may experience these 
medical procedures as an insult, even an attack. After Gloria's home birth, Ministry of Health representatives walked around in the neighbourhood knocking on doors, counting pregnant women. Gloria felt pressured and exposed - and was upset with the hospital procedure.

According to local health authorities, women have different desires due to cultural preferences. Moreover, low levels of formal schooling according to health officials prevent these women from 'knowing better'. 'Culture' has become the problem. Anthropologists have long recognized that as childbirth has become more and more medicalized, this influences how 'normality' in birth is defined (Davis-Floyd and Sargent 1997). Part of these cultural 'problems' are the women who feel perfectly comfortable at home, and do not see why they need the hospital. Some women explained that, after all, everything had gone well the other times they gave birth at home. In a home visit with a brigadista some older women argued that previously childbirth was not considered dangerous, but now they are repeatedly told that they might die in childbirth. Additionally, also noted by Cosminsky (2012) in another Central American context, the local culture values modesty. Several women claimed that home delivery is calmer, easier, familiar and more private; they are covered during birth and usually deliver the baby while in the preferred kneeling position. Women also frequently mentioned pena - embarrassment - at having to spread their legs in front of a stranger, thus confirming the importance of modesty. An older mother of 14 from a barrio not far from the hospital cried out; 'I rather die than spread my legs in front of those strangers!' Women also emphasized that all attention is on the one woman when cared for by a family member or a partera, unlike a hospital birth where nurses and doctors often attend several women at the same time. The women expressed concerns about inattention and negligence from the hospital personnel when in hospital. This reason in particular was why Ana - a 27-year-old mother of three, preferred home birth; 'deliver at home is much better, the attention is all on you and you are not left alone'.

Experiences of poor treatment at the hospital and unpleasant personnel who discriminate against poor, rural women were common complaints. Similar arguments for the support of home birth has been widely documented in many countries (Radoff, Levi, and Thompson 2012; McMahon et al. 2014; Roalkvam 2012). Accounts of women dying in hospital also circulated in rural communities. Many of the stories women told showed their lack of trust in the quality of care - and in the health facilities in general, especially local ones. Women and brigadistas often claimed that things were better at the regional hospital, even if they themselves had no direct experience of them. 'A woman in my barrio almost died at the [local primary] hospital after being given wrong medicine, I think it is better in 
Matagalpa [the regional hospital]', a young woman recalled when being asked about experiences with the healthcare system. As is the case with Gloria, many women judge the local primary hospital incapable of providing good healthcare. These women prefer to stay at home although this implies choosing differently from the 'norm' defined by the public health authorities. Marginal women who do not give birth at a health facility does not only live in the peripheries; they may live close to the hospital, but rejects what is on offer due to an assessment of the care they are given.

Both the pressure and strategies aiming to include women indicate how the state attempts to socialize and manage the 'margins' (Das and Poole 2004). Constant pressure from the hospital - and the brigadistas - makes some women having hospital deliveries after all. To further motivate women to deliver in hospitals, the Ministry of Health adopted a new strategy that allows women to deliver in their preferred position at health facilities. The primary hospital considered implementing this, but staff worried that the obstetrician would not accept women's decisions and desires.

\section{The process of re-marginalization}

Gloria's reasons for refusing hospital births indicate differing perspectives of needs and desires. Health professionals defined Gloria and others who wanted home births rather than hospital births as 'problems'. Health professionals often stressed how they needed to overcome the problems related to home births, in particular the cultural issues. By not complying with public health aims and maternal health strategies and not conforming to the 'standards of normality', people become 'problems', even threats to public health aims. Ministry of Health representatives search the communities for pregnant women, pick women up and even trick them into going, to make sure they give birth in hospital (Kvernflaten 2013). Women reported that health workers told them it was mandatory to stay at casa materna and use the hospital for childbirth. A 41-year-old woman staying at the casa materna and expecting her eighth child said:

I was told that I have to stay here. They shouted at me, scolding me for not have had antenatal check-ups. I was told I am old and that there might be complications. I've stayed here for a month, which I don't have time for.

Health professionals stated that they made efforts to get women to care because it was not acceptable to have any maternal deaths in the municipality. 
The re-defining of 'normality' in maternal health, shaped by the focus on institutional delivery, has also led the government to discredit parteras as birth attendants. Previously, parteras played an important role in providing delivery assistance at the community level. While parteras acquire most of their experience and knowledge informally through traditions and practices, quite a number of them have also received training sessions on delivery assistance. Today, health authorities expect parteras to visit women during pregnancy and advocate for institutional delivery, but not attend to deliveries themselves. This change has led to a conflation of the role of brigadistas and parteras: today many parteras also work as brigadistas, and some parteras thus attend brigadista training sessions. There is no law banning parteras from attending births, but policies and manuals describe their role as not being involved in deliveries. The sanctions against parteras attending births are mainly social. In training sessions, health professionals presented parteras attendance to delivery as a crime and as risky, as the woman might die in the partera's arms. The banning of parteras as birth attendants without proper access to hospital care means removing the only care available to many women. However, some parteras still attend births and some still charge for their services (or receive 'a gift', as charging for services is banned). Health professionals often said they had problems with parteras attending births and charging for services - thereby defining both the woman and the partera as 'problems' and as threats to public health aims of institutional delivery. A 60-year-old partera experienced such social sanctions when hospital personnel searched and threatened her because they had heard that she charged for services. She was very upset and shaking when she told this to the author.

These accounts of Gloria and of parteras acting 'inappropriately' show that these 'marginal women' are not ignored or rendered invisible - they are seen as important and are even searched for. Brigadistas and health professionals come knocking at doors and looking for these women, and the system as a hole is trying to 'manage' (Das and Poole 2004) the women, to get them to comply with maternal health interventions. Marginality is a complex process whereby certain people and ideas are privileged over others, and personal views are cast aside (Tucker 1990; Tsing 1993). Margins are, as this paper has shown, defined by the definition of 'normality'. Re-defining 'normality' as 'skilled birth attendants' or even more narrow as 'institutional delivery' starts a process of re-marginalization of those who have different reasons, desires even, to deliver at home. At times the social production of desire plays into structures of power and inequality, at times it threatens them (Fischer and Benson $2006,4)$. Not conforming to the standard of normality and acting inappropriately result in their being re-marginalized as problems, even threats (Tucker 1990; Ford and Yep 2003). This 
paper suggests that when the norm is re-defined to institutional delivery, the views of women who want to deliver at home, their reason and rational, are ignored. Paradoxically, instead of providing access to maternal healthcare, women feel pressured, forced and exposed - and become re-marginalized ${ }^{6}$.

\section{The shaping of desires and spaces of resistance}

Social relations embedded in kinship, culture, gender, histories and experiences with political economic structures shape women's desires and choices concerning maternal health. If we recognize that humans are social beings brought up in certain historical and social contexts that shape their desires and understanding of the world (Abu-Lughod 2002), we can see that women's desires are shaped contextually and relationally, and that influences what is considered 'good' or 'bad' (Fischer 2014, 12). Relations to the health system, to family and other women in the community, the woman's relation to her children, to her role as a mother, and relations to her (maternal) body - all these shape desires in maternal health. For many women, families and societies, birth is a social, cultural and ritualized event (Jordan 1993). Pregnancy and birth are imbued with practices around the health of the child and the mother, with healing processes and how to conduct 'successful' childbirth (Cosminsky 2012; Jordan 1993). As shown by the value placed on modesty and practices surrounding childbirth in Nicaragua, a 'successful' birth is not always understood or based on the 'needs' defined by biomedicine and public health rationale. Overall wellbeing and illness are socially and culturally contingent. Bodily processes are shaped not only by biological factors: they are also a social product (Polit 2005).

Women's relations to the health system also shape their desires and preferences in maternal health. Histories and experiences with hospital care and staff, and perceptions of what good birth practices and good quality care are, all influence their relationship with and perceptions of the health system (Berry 2008) - and many Nicaraguan women, as do Ana and Gloria above, do not have confidence or trust in that system. Health system encounters are highly contingent: they vary from place to place, and over time, and are indeed persondependent (Corbridge et al. 2005, 21). Women often described poor experiences with one particular health provider, which act to represent the health system as a whole. Such experiences will further influence how women perceive and experience the system. A young woman pregnant with her third child was afraid of going back to the hospital after being treated badly. 'The doctor is odioso [hateful]', she explained. 'He was very inpatient and I think he is only there for the money'. Such stories also travel: people experience the health 
system through the eyes of relatives and neighbours (Roalkvam 2012). Women described their preferences and desires based not only on their own experiences, but also on other women's experiences with the healthcare system. 'My neighbour says that the pain is more complicated at the hospital, that they cut you', a pregnant woman recalled when explaining how she felt about hospital care. 'I think it is easier at home with a partera'. Women did not only sum up experiences based on the outcome of the birth, but also on the way women was treated. Health authorities define rural poor women as undereducated and with the 'wrong' birth culture. Brigadistas, parteras and women often communicated feelings of inferiority in their relation to the hospital and medical personnel. This subordinate identity may shape women's encounters with the health system and thus influence their relation to and perceptions of the hospital.

The husband's perceptions of maternal healthcare is also influential on women's desires as well as agency in making maternal health choices (see Lubbock and Stephenson 2008). Some husbands can be jealous and domineering, reasons often given by women in explaining why some women do not get to care. Yet there are also men who simply want the best for their wives, and do not see hospital care as the optimal alternative. A young husband in a rural remote community expressed concerns on the behalf of his wife; 'Why should she go when they do not take good care of her?' he asked when explaining why he did not want his wife to give birth at the hospital.

Life situations and histories, cultural norms, families, location, socio-economic situation - all shape experiences and influence the woman's preferences and desires in relation to maternal healthcare, and of having home births (Choguya 2015). The choice of not having a hospital delivery is thus shaped within complex sets of relations, positions and experiences, and collides with public health strategies and interventions, and shapes the definition of such women as 'problems'. Many women clearly lack access to services. Some also feel that hospital services cannot provide the kind of care they want. These margins are often where one finds spaces of resistance (hooks 1990). Resistance involves 'taking a stand' or 'withstanding' - to refuse to accept or be changed by something, to fight against, or to express opposition through action or words, often listed as antonyms for compliance. Gloria expressed opposition through her actions and words: 'I will NOT go', and she gave birth to her son at home. Several other women disliked hospital delivery on the same grounds. One partera (and brigadista) living in a community not far from the hospital explained how some women refuse to go to the hospital because of grosería: 
The women dislike it when the doctor reaches inside the vagina, and how they cut, clean and stitch. These things don't happen at home. But even though I try to explain that they should go to the hospital, they refuse. What can I do?

Health professionals stress the importance of these women having a hospital delivery, also training brigadistas and parteras to advocate it. Gloria was hiding from the Ministry of Health, knowing they would scold her for her choices and actions. Gloria and other women like her, also living within spatial and societal marginality, must relate to a health system that they see as incapable of providing the kind of care they want, which makes these women feel distressed and pressured into institutional deliveries. They pull away, and health interventions create resistance, not inclusion. These women do not reject hospital childbirth because it is a

public-health intervention or because it is facility-based as such: theirs is a rejection based on what they themselves consider the best alternative. Here, the choices women make are based on rational decision-making, that take into account whether the care provided is seen to be good (Choguya 2015). Thus they are being pragmatic, yet they reject and pull away - which health professionals see as non-compliance and problematic, given the official health rationale of reducing population-level maternal mortality.

\section{Concluding discussion}

The focus of this paper is on margins, processes of marginalization and the shaping of women's desires. The aim has been to shed new light on maternal health policy and interventions: how measures like requiring skilled birth attendants or narrower - institutional delivery - create and reinforce marginality and create groups that are perceived as problems and obstacles to achieving national and global health goals. Nicaragua has lowered maternal mortality and provided better access to health facilities and facility-based deliveries - a great achievement, especially in a low-resource setting. The aim of reducing maternal mortality among the marginalized is laudable, and women do benefit from such interventions - but many women remain spatially and societally marginalized. Importantly, many feel pressured into a system they see as incapable of providing good quality care.

The paper has argued that biomedicine and public health's power to define and redefine the 'normal', also construct 'margins'. Defining women's maternal health needs in terms of skilled birth attendants and facility-based births constructs women who give birth at home as 'marginal'. But women's desires may diverge sharply from the needs defined by public health authorities. When women choose otherwise than the 'normal', initiate a process 
of re-marginalization of these women as 'problems' or 'non- compliers'. Here is a paradox: when the health system tries to reach everyone, women may feel distressed, pressured to act against their own perceived needs and desires. This creates a space where resistance to or rejection of hospital maternal healthcare can grow, even possibly further distancing such women from services and inclusion in maternal health programmes.

There is a second paradox of 'exclusion' and 'required inclusion' within the same system. The women conceptualized as 'problems' are not directly excluded from the healthcare system, but are required to be included in a system that they deem incapable of providing the kind of care they want - whereas others who may desire hospital care remain excluded, due to spatial and societal marginality. This also illustrates the tensions between the 'margins' as the excluded and ignored, yet of importance to reach and to 'manage'. Furthermore, the re-definition complicates the role of the brigadistas. They can negate marginality by being present, yet the brigadistas, faced with the health system's expectations of advocating institutional delivery, also take part in pressuring women. While brigadistas understand women's home births desires, brigadistas carry the burden and responsibility of maternal deaths in their community (Kvernflaten 2013). This complicates the relationship between women and brigadistas and women may also pull away from the brigadistas' services. The result of the theoretically invisible 'margins' becoming highly visible thus, is further distancing women from maternal healthcare.

Acknowledging the importance of effective biomedical protocols, and calling for such interventions not to be separated from local context has been made by several scholars (Berry 2008; Choguya 2015; Kruske and Barclay 2004; Spangler 2012). Furthermore, as Berry (2008) points out, health workers must be willing to acknowledge and negotiate the spaces where biomedical protocols and local expectations conflict. This also relates to discussions of the skills of the skilled birth attendant and quality of care; it is also shown elsewhere that facility-based delivery does not necessarily mean that care is of good quality (Pérez et al. 2011; Spangler 2012), yet understanding local opinions of quality of care make possible negotiating such conflicting spaces.

To understand what matters to women and why they make their choices, it is essential to see desires and choices in their social context. We also need to move beyond a uniform definition of marginality in public health as 'lack of access', and recognize the differing situations of women, and the complexities shaping preferences, choices and desires. That can shift the focus from individual health behavioural models to the larger social spheres where these behaviours are enacted and rendered meaningful (Ford and Yep 2003, 245). We can 
then move away from seeing these women as 'problems' and 'non-compliers', and start focusing on the larger context in which they live - including the health system and other social conditions. Just as 'normality' is continually re-defined, people's desires and preferences are also flexible and changing. If the focus can be on strengthening the health system and taking account of local understandings of the quality of care, then women's desires in maternal health may change accordingly. The goal of including 'the marginalized' may come closer, as services may actually fit the desires as well as needs of women.

Perhaps these women still want home birth even with a strengthened health system, improved quality of care and trust established. But then they would have a better foundation for making their choices, and they would have access to emergency care if severe complications should develop. Although some women perceive home birth as familiar and reassuring, for others, the home may lack the resources required to make birth a safe experience. Moreover, if marginality is a factor contributing to poor health, then improvements in the health sector alone will not suffice to improve maternal health (Polit 2005, 227). While a poor health system is part of the problem, other factors - such as poverty and gender relations - also contribute to keeping women at the margins of maternal healthcare.

'The margin' is a site of intervention, but it is also a lived reality (Nijhawan 2005, 271). Failure to recognize this lived reality is a major barrier to improving maternal health among the most marginalized women of rural Nicaragua.

\section{Acknowledgments}

The author wishes to thank all the women in Nicaragua who shared their experiences, perceptions and desires and to express gratitude to the parteras and brigadistas. Further thanks to Sidsel Roalkvam, Katerini Storeng and Johanne Sundby for reviewing drafts and providing valuable and constructive advices, and to the anonymous reviewers for their insightful comments. This study holds ethics approval from the Norwegian Social Science Data Services (NSD), and approval from local health authorities in Nicaragua. This study was supported by the Centre for Development and the Environment (SUM), University of Oslo, as part of the author's PhD thesis.

\section{Notes}

1. Inverted commas around terms such as marginal women, needs, desires etc. indicate that perceptions of what these encompass may differ, they are not absolute concepts. 
2. In 2012, 2031 live births were expected, on the basis of 2011 figures.

3. Machismo is described as a deeply-ingrained cult of the male, which influences gender relations (Sternberg 2000). This paper does not discuss machismo, but refers to how local people use the term.

4. There are about 0.4 doctors per 1000 inhabitants on average in Nicaragua, yet higher in urban areas. The capital has 1.1 doctors per 1000 inhabitants. (Serneels 2014).

5. The casa materna later moved to the hospital. The number of beds, funding and payment for services may have changed.

6. Reddy (2005) also describe how Hijras - Indias 'third sex', become re-marginalized as public health policies change their marginality

\section{References}

Abu-Lughod, Lila. 2002. "Do Muslim Women Really Need Saving? Anthropological Reflections on Cultural Relativism and Its Others." American Anthropologist 104 (3):783-790. doi: $10.2307 / 3567256$.

Austveg, Berit. 2011. "Perpetuating power: some reasons why reproductive health has stalled." Reproductive Health Matters 19 (38):26-34. doi: 10.1016/s0968-8080(11)38583-7.

Berry, N. S. 2008. "Who's judging the quality of care? Indigenous maya and the problem of "not being attended"." Medical Anthropology 27:164 - 189.

Choguya, Naume Zorodzai. 2015. "Traditional and Skilled Birth Attendants in Zimbabwe: A Situational Analysis and Some Policy Considerations." Journal of Anthropology 2015:11. doi: $10.1155 / 2015 / 215909$.

Corbridge, Stuart, Glyn Williams, Manoj Srivastava, and René Véron. 2005. Seeing the State: Governance and Governmentality in India. Cambridge: Cambridge University Press.

Cosminsky, Sheila. 2012. "Birth and Blame: Guatemalan Midwives and Reproductive Risk." In Risk, Reproduction, and Narratives of Experience, edited by Lauren Fordyce and Amínata Maraesa. Nashville, TN: Vanderbilt University Press.

Das, Veena, and Deborah Poole. 2004. "State and Its margins: Comparative Ethnographies." In Anthropology in the Margins of the State, edited by Veena Das and Deborah Poole, 3-33. Santa Fe, NM: School of American Research Press.

Davis-Floyd, Robbie E., and Carolyn F. Sargent. 1997. "Introduction. The Anthropology of Birth." In Childbirth and Authoritative Knowledge: Cross-Cultural Perspectives, edited by Robbie E. Davis-Floyd and Carolyn F. Sargent. London: University of California Press.

Ecks, Stefan, and William S. Sax. 2005. "The ills of marginality: new perspectives on health in South Asia." Anthropology \& Medicine 12 (3):199-210. doi: 10.1080/13648470500291287.

Feierman, S., A. Kleinman, K. Stewart, P. Farmer, and V. Das. 2010. "Anthropology, knowledge-flows and global health." Global Public Health 5 (2):122-128. doi: 10.1080/17441690903401338.

Fischer, Edward F. 2014. The Good Life: Aspiration, Dignity, and the Anthropology of Wellbeing. Stanford, CA: Stanford University Press.

Fischer, Edward F., and Peter Benson. 2006. Broccoli and desire: global connections and Maya struggles in postwar Guatemala. Stanford, CA: Stanford University Press. 
Ford, Leigh Arden, and Gust A. Yep. 2003. "Working along the Margins: Developing Community-based Strategies for Communicating about Health with Marginalized Groups." In Handbook of Health Communication, edited by Teresa L. Thompson, Alicia Dorsey, Katherine I. Miller and Roxanne Parrott, 241-262. Mahwah, NJ: Laurence Erlebaum Associates.

Gurung, Ghana S., and Michael Kollmair. 2005. Marginality: concepts and their limitations. In IP6 Working Paper No. 4. NCCR North-South, Zurich.

Harvey, Steven. A., Yudy Carla Wong Blandón, Affette McCaw-Binns, Ivette Sandino, Luis Urbina, César Rodríguez, Ivonne Gomez, Patricio Ayabaca, and Sabou Djibrina. 2007. "Are skilled birth attendants really skilled? A measurement method, some disturbing results and a potential way forward." Bulletin of the World Health Organization 85 (10):783-90.

hooks, bell. 1990. "Talking back." In Out There: Marginalization and Contemporary Cultures, edited by Russell Ferguson, Martha Gever, Trinh T. Minh-ha and Cornel West, 337-340. New York: New Museum of Contemporary Art.

Inter-American Development Bank. 2004. Nicaragua. Improving Maternal and Child Health: Performance Driven-loan. NI-L1001.

Inter-American Development Bank. 2011. Programa de Mejoramiento de la Salud Familiar y Comunitaria en Municipios de Alta Vulnerabilidad Social: Perfil de proyecto Nicaragua. NIL1054.

Jordan, Brigitte. 1993. Birth in four cultures: a crosscultural investigation of childbirth in Yucatan, Holland, Sweden, and the United States. 4th ed. Prospect Heights, IL: Waveland Press.

Kruske, Sue, and Lesley Barclay. 2004. "Effect of shifting policies on traditional birth attendant training." Journal of Midwifery \& Women's Health 49 (4):306-311. doi: http://dx.doi.org/10.1016/i.jmwh.2004.01.005.

Kvernflaten, Birgit. 2013. "Meeting targets or saving lives: Maternal health policy and millennium development goal 5 in Nicaragua." Reproductive Health Matters 21 (42):32-40. doi: 10.1016/s0968-8080(13)42728-3.

Leimgruber, W. 2004. Between Global and Local: Marginality and Marginal Regions in the Context of Globalization and Deregulation: Ashgate.

López, Ismael. 2014. "Subregistro de muerte materna." Confidencial, February 17. http://www.confidencial.com.ni/articulo/16146/subregistro-de-muerte-materna.

Lubbock, Lindsey Ann, and Rob B. Stephenson. 2008. "Utilization of maternal health care services in the department of Matagalpa, Nicaragua." Pan American Journal of Public Health 24 (2):7584 .

McMahon, Shannon A., Asha S. George, Joy J. Chebet, Idda H. Mosha, Rose NM. Mpembeni, and Peter J. Winch. 2014. "Experiences of and Responses to Disrespectful Maternity Care and Abuse During Childbirth; a Qualitative Study with Women and Men in Morogoro Region, Tanzania." BMC Pregnancy and Childbirth 14 (1):268.

Ministerio de Salud. 2014. Informe de gestión en salud 2013. Managua, Nicaragua.

Nijhawan, Michael. 2005. "Deportability, Medicine, and the Law." Anthropology \& Medicine 12 (3):271-285. doi: 10.1080/13648470500291436.

Pan American Health Organization. 2007. Nicaragua. In Health in the Americas 2007. Volume II: Countries. Washington, DC: PAHO.

Pan American Health Organization. 2008. Health systems profile Nicaragua: monitoring and analyzing health systems change/reform. Washington, DC: PAHO.

Peattie, Lisa R. 1980. "Anthropological Perspectives on the Concepts of Dualism, the Informal Sector, and Marginality in Developing Urban Economies." International Regional Science Review 5 (1):1-31. doi: 10.1177/016001768000500101.

Pérez, Wilton, Rodolfo Peña, Lars-Åke Persson, and Carina Källestål. 2011. "Tracking progress towards equitable child survival in a Nicaraguan community: neonatal mortality challenges to meet the MDG 4." BMC Public Health 11 (1):1-7. doi: 10.1186/1471-2458-11-455. 
Polit, Karin M. 2005. "The Effects of Inequality and Relative Marginality on the Well-being of Low Caste People in Central Uttaranchal." Anthropology \& Medicine 12 (3):225-237. doi: $10.1080 / 13648470500291345$.

Radoff, Kari A., Amy Levi, and Lisa M. Thompson. 2012. "From Home to Hospital: Mistreatment of Childbearing Women and Barriers to Facility-based Birth in Nicaragua." International Journal of Childbirth 2 (1):40-50.

Ray, Eileen Berlin. 1996. "Introduction." In Communication and Disenfranchisement: Social Health Issues and Implications, edited by Eileen Berlin Ray. Hillsdale, NJ: Lawrence Erlbaum

Reddy, Gayatri. 2005. "Geographies of contagion: Hijras, Kothis, and the politics of sexual marginality in Hyderabad." Anthropology \& Medicine 12 (3):255-270. doi: 10.1080/13648470500291410.

Roalkvam, S. 2012. "Stripped of rights in the pursuit of the good: the politics of gender and the reproductive body in Rajasthan, India." In Development and environment: practices, theories, policies., edited by Kristian Bjørkdahl and Kenneth Bo Nielsen. Oslo: Akademika forlag

Serneels, P. 2014. " Internal Geographical imbalances: The Role of Human Resources Quality and Quantity." In Encyclopedia of Health Economics, edited by A.J. Culyer, 91-102. San Diego: Elsevier Science.

Silva, José Adán. 2010. "Nicaragua: Mortalidad Materna en el Subibaja de Opiniones [Nicaragua: Maternal Mortality in the Seesaw of Opinions]." IPS Agencia de noticias, April 19. http://www.ipsnoticias.net/2010/04/nicaragua-mortalidad-materna-en-el-subibaja-deopiniones/.

Spangler, S. A. 2012. "Assessing skilled birth attendants and emergency obstetric care in rural Tanzania: the inadequacy of using global standards and indicators to measure local realities." Reproductive Health Matters 20 (39):133-41. doi: 10.1016/s0968-8080(12)39603-4.

Sternberg, Peter. 2000. "Challenging machismo: promoting sexual and reproductive health with Nicaraguan men." Gender and Development 8 (1):89-99. doi: 10.2307/4030311.

Tesler, L. E. 2010. "The social relations of health care and household resource allocation in neoliberal Nicaragua." BMC International Health and Human Rights 10:1-13. doi: 10.1186/1472-698X$10-9$.

Tsing, Anna Lowenhaupt. 1993. In the realm of the diamond queen: marginality in an out-of-the-way place. Princeton, NJ: Princeton University Press.

Tucker, Marcia. 1990. "Director's Foreword." In Out There: Marginalization and Contemporary Cultures, edited by Russell Ferguson, Martha Gever, Trinh T. Minh-ha and Cornel West. New York: New Museum of Contemporary Art.

Unicef. 2012. Country Profile; Nicargua. Maternal, Newborn \& Child Survival. Statistics and Monitoring Section / Policy and Practice.

USAID. 2008. Nicaragua Health Program Evaluator. Edited by Jack Reynolds and Annette Bongiovanni. Washington, DC: USAID.

Yamin, A. E., and V. M. Boulanger. 2014. "Why global goals and indicators matter: the experience of sexual and reproductive health and rights in the millennium development goals." Journal of Human Development and Capabilities 15 (2-3):218-231. doi:

10.1080/19452829.2014.896322. 